\title{
We Hommage à Gérard Joncoux
}

érard Joncoux, un homme dont la présence fut bienveillante par sa seule manière d'être, par sa façon d'occuper l'espace. Et sûrement un peu plus car, psychologue de formation et de conviction, il était un sacré psychanalyste. Un Sacre qu'il ne tenait pas uniquement de l'École Freudienne de la rue Claude Bernard, mais bien plutôt de ses postures de réserve à l'égard de l'émiettement des institutions. Un homme de bon sens. Pour dire les choses autrement, un sacré bonhomme, ce psychanalyste, pipe au bec, accompagné de son chien, déambulant dans l'hôpital de Ville Évrard, d'un côté de la N 34, ou dans l'hôpital de Maison Blanche, de l'autre côté. Prenant son temps, au rythme de son animal s'arrêtant et discutant : une façon à lui de prendre les températures et de faire du lien, de se réapproprier ce climat méditerranéen, celui de son enfance.

Avec lui, ces rencontres impromptues libéraient le cours des choses, celles d'un temps qui va comme il va, celles d'un temps qui passe, ou qui nous regarde passer. Et il est parti comme ça, comme il avait vécu. Discrètement, sans faire de bruit, sûrement surpris d'être autant entouré : des patients assurément, des élèves ou des stagiaires aussi, des collaborateurs, connus ou anonymes, des gens, tout simplement, des gens qui aimaient son être au monde. Mais que dire des gens qu'on aime, des gens dont on est fier de les avoir approché, de les avoir rencontré, d'avoir partagé quelque chose avec eux? Que dire? Peut être savoir s'abstenir, tout en restant présent. Ses obsèques furent une réponse, une belle réponse pour une belle personne.

Il y avait chez Gérard (parler déjà de lui au passé est douloureux) quelque chose qui protège et sécurise, qui accueille et vous fait accueillir, quelque chose qui vous incite à dire sans attendre une réponse, au moins de lui, mais une réponse hors du temps, en dehors de l'espace, une réponse intérieure touchant pourtant à l'universel. Tout ça peut se nommer. Oui, bien sûr! Il dialoguait avec lui-même, ouvertement, une discrète fiction, et soumettait à notre appréciation ce débat qu'il venait de tenir, devant nous et pour nous. Je parle de nos réunions du jeudi sur le terrain d'un service de psychiatrie adulte dont, tous deux nous relevions. Car pour le service, le miracle Joncoux fut Fadilha à qui il sut rendre la vie. Chacun se souvient.

Et cette dernière plaisanterie de Gérard, et qui lui va si bien, concernant sa brève et définitive hospitalisation: " tu penses quand même pas que je vais casser ma 
$\mathbb{W}$

232 [psychologie clinique 㐘 $\mathrm{n}^{0} 45$ 䊅 2018/1

pipe ! ». Gérard est au Père Lachaise depuis ce 10 Janvier 2017. Et tous, nous pensons à Annie, son épouse de tant d'années, à ces deux grandes filles, et à Félicien, son garçon.

Serge G. Raymond 